\title{
Formação continuada de professores: a utilização de trilhas interpretativas como instrumento pedagógico
}

\section{Kamila Marques Pedrosa ${ }^{1}$, Suellen da Silva Santos ${ }^{2}$, Edardna Suzana Andrade ${ }^{3}$, Ewerton Freire Rodrigues ${ }^{3}$, Jackson dos Santos Silva ${ }^{3}$, Diogo Anderson Fonseca Santana $^{3}$ e Wilson José Xavier Félix ${ }^{3}$}

\author{
${ }^{1}$ Universidade Estadual da Paraíba. Laboratório EcoTropics. Campus I. Rua \\ Baraúnas, 351. Universitário, Campina Grande-PB, Brasil (CEP 58429-500). \\ *E-mail: kamila_biopb@hotmail.com. \\ ${ }^{2}$ Universidade Federal da Paraíba. Centro de Ciências Exatas e da Natureza. \\ Departamento de Sistemática e Ecologia. Laboratório de Etnobiologia e Ciências \\ Ambientais. Campus I. João Pessoa-PB, Brasil (CEP 58051-900). \\ ${ }^{3}$ Universidade Federal da Paraíba. Campus II. Rodovia PB-079. Areia-PB, Brasil \\ (CEP 58397-000).
}

Resumo. 0 estudo teve como objetivo intervir na construção de uma ação de formação continuada de professores para utilização de trilhas interpretativas como processo pedagógico, e analisar reflexivamente sobre os diferentes aspectos dessa intervenção. A formação foi realizada com professores e professoras da rede estadual de ensino do Município de Areia, Estado da Paraíba. As atividades desenvolvidas com os professores foram parte do projeto PROLICEN (Programa de Licenciaturas) e foram realizadas em dois momentos distintos. Para coleta dos dados foi utilizado questionário, observação e grupo focal. 0 primeiro momento teve a presença de nove professores e ocorreu por meio da formação teórica em sala de aula mediado por discussões sobre temas educação ambiental, formação docente, unidade de conservação, metodologias ativas, trilhas interpretativas, Mata do Pau Ferro e exposição dos recursos pedagógicos. O segundo momento de formação ocorreu na Mata do Pau Ferro com a presença de quatro professores que participaram das trilhas interpretativas demarcada com pontos estratégicos e com temas pré-estabelecidos pelos monitores, a fim de estabelecer discussões sobre diversos temas. A partir dessa formação continuada foi possível elucidar que formações continuadas que envolvam os professores e os façam refletir sobre suas metodologias em sala de aula, visto que, atualmente o percurso das formações tem enfadado os docentes, mas é notório que os mesmos compreendem a necessidade de espaços formativos, principalmente, com temas relevantes para sociedade moderna e que tratam de contextos transdisciplinares.

Recebido

$11 / 03 / 2020$

Aceito

29/04/2020

Publicado

$30 / 04 / 2020$

Acesso aberto

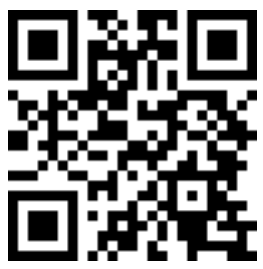

ORCID

(D) 0000-0003-1976-3545 Kamila Marques

Pedrosa

D) 0000-0001-7280-7856 Suellen da Silva Santos

ISSN 2359-1412/RBGAS-2020-0013/2020/7/15/31/439

Rev. Bras. Gest. Amb. Sustent.

http://revista.ecogestaobrasil.net 
Palavras-chave: Formação docente; Educação ambiental; Metodologias ativas.

\begin{abstract}
Continuing teacher education: The use of interpretive trails as a pedagogical tool. The objective of this study was to intervene in the construction of actions to continuous teacher training for the use of interpretive trails as a pedagogical process, and a reflexively analyze the different aspects of that intervention. The training was carried out with teachers from The State Education Network in the Municipality of Areia, State of Paraíba, Brazil. The activities developed with the teachers were part of the PROLICEN project (Bachelor's Program) and took place at two different times. In the beginning, there was the participation of nine teachers, and it was produced through theoretical classroom training mediated by discussions on environmental education, teacher training, conservation unit, active methodologies, interpretive trails, Mata do Pau Ferro, and exhibition of the pedagogical resources. The second stage of training took place in the Mata do Pau Ferro with the presence of four teachers who participated in the interpretive trails demarcated with strategic points and with pre-established themes by the monitors, in order to establish discussions on various topics. From this continuous training it was possible to elucidate that continuous training involving teachers and make them reflect on their methodologies in the classroom, since, currently the course of the training has annoyed the teachers, but it is well known that they comprise the need for training spaces, mainly, with topics relevant to modern society and dealing with transdisciplinary contexts.
\end{abstract}

Keywords: Teachers training; Environmental education; Active Methodologies

\author{
0000-0001-7192-7389 \\ Edardna Suzana \\ Andrade \\ (ㄷ) 0000-0002-4232-5052 \\ Ewerton Freire \\ Rodrigues \\ (D) 0000-0001-5722-3406 \\ Jackson dos Santos \\ Silva \\ (ㄱ) 0000-0001-5872-0252 \\ Diogo Anderson \\ Fonseca Santana \\ D 0000-0001-6914-3825 \\ Wilson José Xavier \\ Félix
}

\section{Introdução}

A formação continuada de professores dentro de temáticas da educação ambiental passou a ser reconhecido desde 1973 pela Organização das Nações Unidas para Educação, Ciência e Cultura (UNESCO). Desde os anos 1990, as formações docentes no Brasil têm-se intensificado como uma nova ferramenta para construção do perfil profissional dos professores (Veiga, 1998).

No entanto, as formações têm sido construídas como modelos voltados para o acúmulo, repasse de conhecimento e têm sido descontextualizadas com a prática docente (Silva e Araújo, 2005). Essa transferencialidade de informações tem comprometido o significado das formações, que de acordo com Pacheco (2011) está havendo um acúmulo de certificações sem relevância para autoformação e comprometimento para sala de aula.

As formações continuadas devem ser espaços que permitam a transformação da escola, permitindo aos professores refletirem suas práticas para, consequentemente, viabilizar o desenvolvimento de melhores formas para aquisição do conhecimento e capacidade reflexiva dos estudantes para a construção da cidadania (Deus e Mendes, 2011; Gonzaga, 2013). 
Uma nova forma de pensar as formações continuadas passou a vislumbrar a construção do conhecimento e teorias sobre a prática docente, os quais devem reconstruir com a mão própria suas necessidades, partindo do já existente para uma reflexão crítica da ação-reflexão-ação, de modo criativo e adequando às necessidades da sociedade (Demo, 2011).

Para isso há uma necessidade de formação docente, e essa atribuição de formação está posta as instituições de nível superior (Silva, 2011). As universidades possuem responsabilidade tanto na produção científica e construção de políticas nesse campo, quanto na formação de profissionais de todas as áreas, principalmente, docentes que atuarão em todos os níveis do ensino (Silva, 2011). Para tanto, as universidades devem agir por meio de investigações e do desenvolvimento de metodologias, tecnologias e ferramentas ecologicamente adequadas e socialmente justas, cujo empoderamento por parte da sociedade é a chave para a sua implementação (Silva, 2011).

Entre as novas maneiras de trabalhar em sala de aula, as metodologias ativas desenvolvem premissas para o ensino-aprendizagem por meio da autonomia dos estudantes e devem ser engajadas por atividades complexas, principalmente, por experimentações, que possuam um viés estimulante, significativo e interativo por meio de tecnologias adequadas orientadas pelos professores (Gemignani, 2012).

As metodologias ativas, segundo Freire (2006) dizem respeito a uma concepção educativa que estimula processos construtivos da ação e reflexão por meio de situações de problemas reais que devem ser estimulados pelo docente para que o estudante reflita e decida os melhores meios de resolução dos atos propostos, visando a uma educação transformadora em diferentes contextos.

Dentre essas tecnologias, as trilhas interpretativas, segundo Leff (1999), tornam-se uma ferramenta metodológica ativa que costuma entusiasmar participantes do processo de ensino-aprendizagem de maneira concreta pela interpretação dos conceitos formulados em sala de aula para o contexto real da sociedade que, no presente caso, aborda a reflexão do agir fora das paredes da escola.

As trilhas interpretativas caracterizam-se por favorecer a percepção do ambiente promovendo o contato holístico entre ser humano e a natureza, possibilitando o conhecimento da biodiversidade e história do ambiente, constituindo um instrumento pedagógico importante (Minopoli et al., 2004).

Partindo do princípio que docentes são os principais responsáveis em dialogar de maneira recíproca o conhecimento científico e transformador de valores, a Política Nacional de Educação Ambiental (PENEA), por meio da Lei no 9.795/1999 (Brasil, 1999), traz em seus princípios a aplicabilidade da modalidade transversal referente a educação ambiental e, portanto, o currículo escolar deve propor reformulações metodológicas que integrem o desenvolvimento interdisciplinar dos professores (Guerra e Abílio, 2006). Compreendemos que essa investigação é relevante por trazer à tona a formação continuada de professores para educação ambiental e, principalmente, no âmbito das trilhas interpretativas. Além disso, é uma temática que carece de estudos que possam pensar na melhoria do processo de ensino, além de evidenciar que os resultados aqui identificados irão contribuir com o aperfeiçoamento das atividades de formação dos professores e consequentemente com suas futuras aulas.

Desta forma, o presente estudo teve como objetivo norteador intervir na construção de uma ação de formação continuada de professores para utilização de trilhas interpretativas como processo pedagógico, e analisar reflexivamente sobre os diferentes aspectos dessa intervenção. 


\section{Material e métodos}

\section{Caracterização da pesquisa}

0 presente estudo trata-se de uma pesquisa com abordagem qualitativa, pois permite observar os sujeitos (Prodanov e Freitas, 2013), buscando compreender a relação do mundo real e a forma que o sujeito pensa sobre ele, portanto, compreender o processo de formação continuada de professores sobre as trilhas interpretativas. A pesquisa é participante, em virtude das interações entre os mediadores (estudantes bolsistas e coordenador do projeto) e os membros das situações investigadas (Gil, 1991).

\section{Sujeitos da pesquisa}

As atividades aqui registradas foram realizadas com professores representantes de três escolas da rede pública estadual, localizadas no Município de Areia, Estado da Paraíba. Os participantes da pesquisa foram oito professores, das disciplinas de Ciências Biológicas, História, Educação Física, Geografia, Português e uma discente do Curso de Graduação em Geografia. Todos foram apresentados ao objetivo do estudo e convidados a participar por meio de um formulário de inscrição. Por motivos éticos categorizamos as respectivas disciplinas por professores em algarismo romano.

\section{Locais da pesquisa}

O Município de Areia possui três escolas estaduais. 0 primeiro momento da formação foi realizado no espaço físico de uma das escolas participantes da formação continuada. Enquanto que o segundo momento foi conduzido na Mata do Pau Ferro, ambos pertencentes ao Município de Areia, Estado da Paraíba e, portanto, serão tratados juntos como locais de pesquisa.

O Município de Areia está localizado na Microrregião do Brejo Paraibano, atualmente a sua população é de aproximadamente de 23.829 habitantes, com estimação populacional de 23.110 no ano de 2015, conforme dados do Instituto Brasileiro de Geografia e Estatística (IBGE, 2010). A área territorial do município corresponde a $266,596 \mathrm{~km}^{2}$ com densidade demográfica de $88,42 \mathrm{hab} / \mathrm{km}^{2}$, com temperatura média anual oscilando em torno dos $23,5^{\circ} \mathrm{C}$ (FAMUP, 2013) (Figura 1).

O Parque Estadual Mata do Pau-Ferro está situado no Sítio Vaca Brava, Brejo de Altitude do Município de Areia ( $6^{\circ} 58^{\prime} 12^{\prime} \mathrm{S}$ e $35^{\circ} 42^{\prime} 15^{\prime} \mathrm{W}$ ), na mesorregião do Agreste Paraibano, perfazendo uma área de 600 hectares de bioma Mata Atlântica. O Parque da Mata do Pau Ferro situa-se aproximadamente $7,2 \mathrm{~km}^{2}$ do centro da cidade de Areia, estado da Paraíba, Nordeste do Brasil. 0 parque é uma Unidade de Conservação do tipo integral, criado no ano de 1992 e constitui-se como um dos últimos remanescentes de Mata Atlântica do Nordeste representando 1\% de mata de Brejo de Altitude que ainda existe na Paraíba (Figura 2). 0 parque tem por objetivos proteger a beleza cênica; preservar a biodiversidade e os ecossistemas naturais, admitindo o uso indireto e controlado dos recursos; possibilitar a realização de estudos, pesquisas e trabalhos de interesse científico; oferecer condições para recreação, turismo e a realização de atividades educativas e de consciência ecológica.

\section{Descrição da pesquisa}

0 presente trabalho teve como base para análise, as ações formativas realizadas no projeto de PROLICEN intitulado: Ver-Julgar-Agir: A trilha ecológica como recurso pedagógico para a educação ambiental, que objetivou refletir as trilhas interpretativas como recurso pedagógico complexo com amplas possibilidades e contribuições para o ensino formal, intimamente ligada à metodologia do ver-julgar-agir, método próprio de uma construção de proposta pedagógica para a educação ambiental (Hammes, 2004). 
A coleta das informações ocorreu no mês de março de 2019. 0 pré-requisito para participação da formação continuada foi para professores e professoras da rede pública do Município de Areia, contratados ou efetivos. Foi explicado a todos o objetivo da formação e entregue folder.
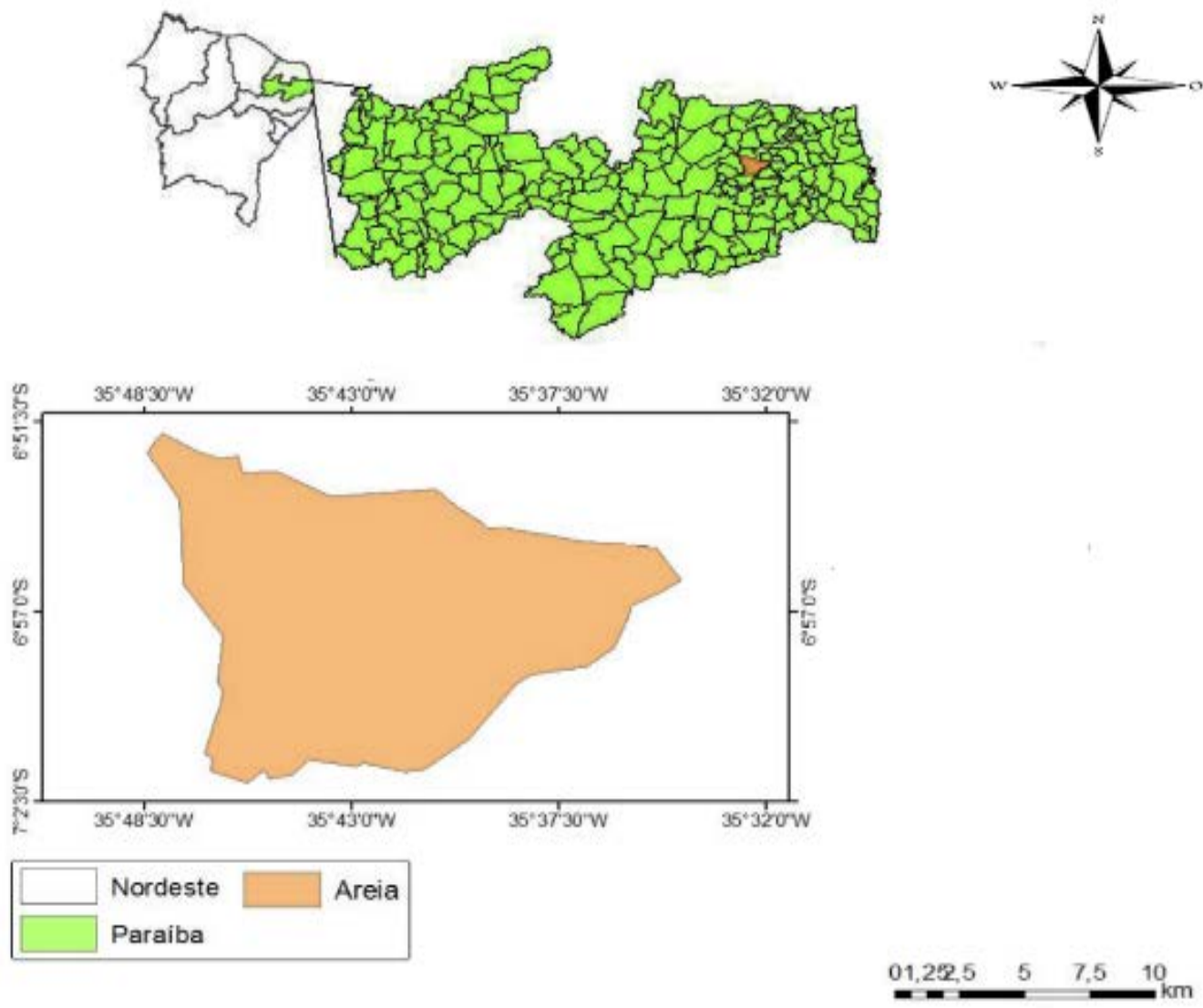

Figura 1. Mapa de localização do Município de Areia, Estado da Paraíba, Brasil. Fonte: Diogo Santana (2018). 


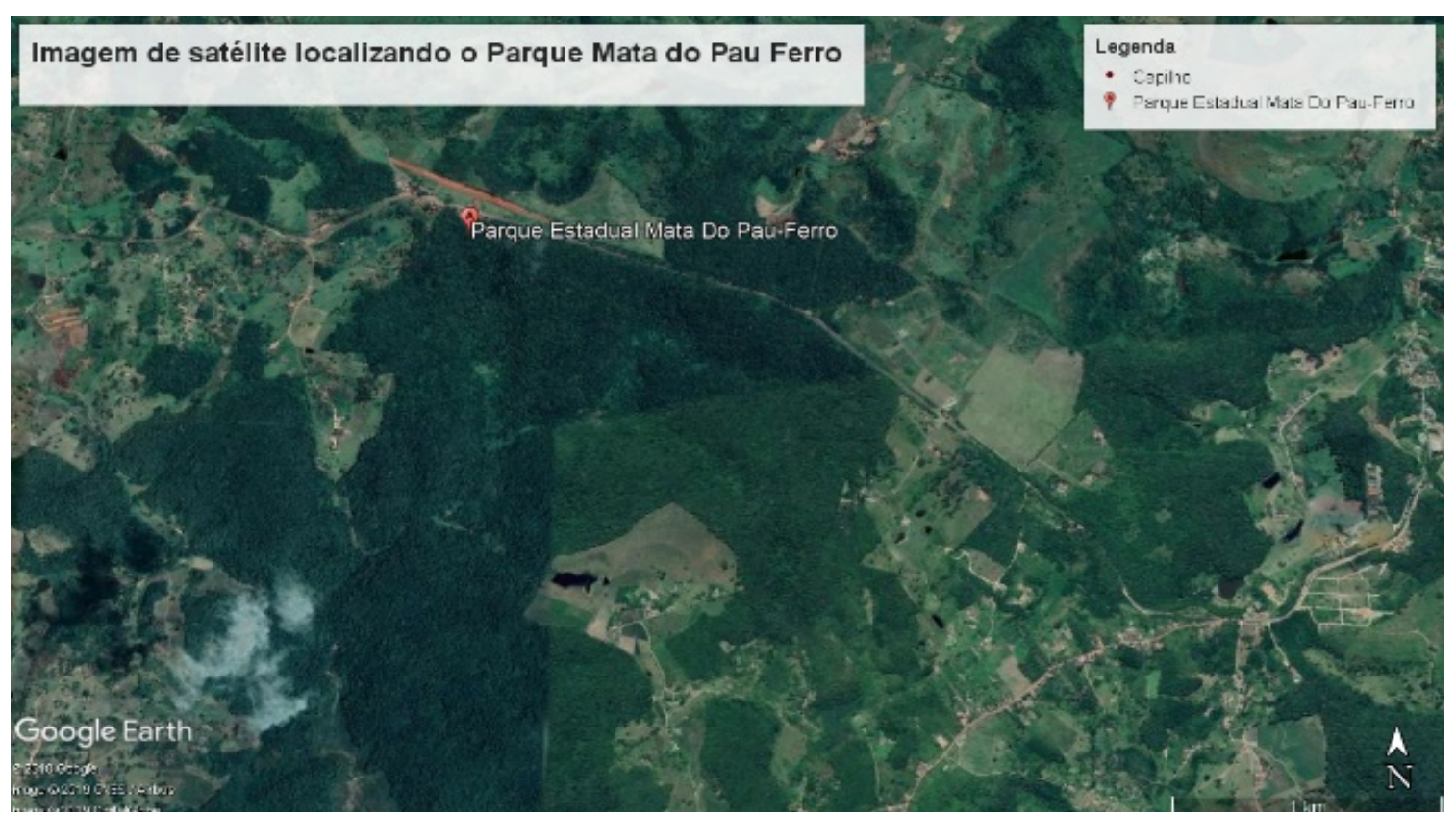

Figura 2. Imagem de satélite localizando o Parque Estadual Mata do Pau Ferro, Areia, Paraíba, Nordeste do Brasil. Fonte: Google Maps (2019).

A formação foi estruturada e organizada em dois momentos. 0 primeiro momento foi destinado a contextualização do estudo de Metodologia Ativa e como utilizar as trilhas interpretativas como ferramenta pedagógica. 0 segundo momento foi levar os professores para a Mata do pau Ferro, no intuito de colocar em prática os conteúdos das respectivas disciplinas e a importância de trabalhar as trilhas interpretativas. A trilha possuía pontos estratégicos marcados que possibilitaram provocar discussão sobre como poderia ser trabalhado determinados assuntos.

\section{Instrumento de coleta de dados}

Utilizamos durante o primeiro momento da formação questionários estruturados com perguntas fechadas, com finalidade de realizar um diagnóstico inicial. Dentre as perguntas do questionário abordamos apenas quatro informações, estas foram previamente pensadas: Qual seu tempo de atuação em sala de aula? Você acha que a formação docente continuada auxilia na aplicação de novos recursos? Já fez outra formação continuada? Qual (quando houver)? 0 que você espera desse minicurso?

Durante os dois momentos da formação (na sala de aula e na trilha interpretativa), foram observadas as relações entre professor e mediadores (alunos e coordenador do projeto), por meio de uma observação assistemática, essa observação se trata de uma técnica que ocorre de forma livre sendo utilizado nas fases inicias da pesquisa, no sentido de conhecer os sujeitos envolvidos e o tipo de observação sistemática requer planejamento para registrar os fenômenos que serão investigados (Rúdio, 2002), para este último caso descrevemos um roteiro de observação.

No fim do segundo momento foi realizado a técnica de pesquisa grupo focal que consiste em coletar dados de interação grupal por meio de debate de idéias, incluindo estratégias, afim de produzir informações (Morgan, 1996).

\section{Análise de dados}

No intuito de compreender os dados obtidos na formação através de questionários, observação e grupo focal utilizamos o procedimento de triangulação, que permite analisar diferentes abordagens metodológicas e diferentes perspectivas teóricas distintas para 
tratar um fenômeno e diminuir as chances de distorções, de modo a consolidar a construção do estudo que está sendo investigado (Flick, 1992).

\section{Resultados}

\section{Primeiros momentos da formação docente: troca de experiências e conhecimentos na sala de aula}

Os resultados aqui apresentados são procedentes da intervenção pedagógica com oito professores, das disciplinas de Ciências Biológicas, História, Educação Física, Geografia, Português e uma discente do curso de Geografia. Essa intervenção foi realizada em dois encontros distintos, que tiveram duração de 4 horas/aulas, totalizando 8 horas/aula.

A efetivação da construção dessa formação foi árdua, houveram outras tentativas de reunir os professores. Na primeira tentativa, realizada no mês de novembro de 2018, apenas uma professora se fez presente no encontro da formação, que acabou não acontecendo. Essa situação pode ser atrelada à longa jornada de trabalho do corpo docente e falta de anseio em participar de formações continuada, principalmente, em áreas que não fazem parte de interesse e atuação dos docentes, bem como, o período letivo pode ter sido um fator influenciador para não participação dos professores, visto que, estavam sobrecarregados de atividades.

Perante essa situação, uma nova estratégia foi pensada, buscou-se, então, levar o coordenador do projeto para convidar pessoalmente gestores e professores das escolas e, preparamos um folder com o intuito de envolver os docentes, apresentando mais detalhadamente as atividades do minicurso. Nesse momento da nova abordagem, todos professores e professoras das três escolas estaduais da cidade de Areia, estado da Paraíba foram convidados a participar do projeto.

No primeiro momento, foi desenvolvido o curso em sala de aula, o qual foi permitido contextualizar as principais temáticas sobre as trilhas interpretativas. Portanto, antes de iniciar as atividades da formação, todos os professores que encontravam-se presentes na sala, foram convidados a responder questionários semiestruturados sobre 0 assunto, no entanto, aqueles docentes que chegaram na sala de aula após o início da exposição da formação não participaram dos questionários, pois, o intuito seria realizar o diagnóstico sem que houvesse a explanação do assunto.

Para o primeiro momento, seis professores participaram, respondendo as seguintes questões: tempo de atuação em sala de aula? Se já fez outra formação continuada? Se achavam que a formação docente auxiliava na aplicação de novos recursos? O que esperavam com o minicurso?

Entre os profissionais que participaram da entrevista, todos possuem atuação docente relevante, visto que, possuem experiência em sala de aula, constituindo vinte anos de atuação, dez anos, oito anos, quatro anos e houve uma situação de um professor que não compreendeu a pergunta e uma resposta de uma estudante que ainda não possui atuação.

Quanto à existência de participação em outras formações continuadas, quatro docentes alegaram não ter vivenciado uma formação, enquanto dois participaram, um a respeito de Fundamentos da Educação e o outro professor em Economia solidária, Gira mundo Finlândia e Ensino para pessoas com deficiência visual, esses dois últimos possuem maiores tempos de atuação docente.

Quando se trata do quanto os professores acreditam na potencialidade da formação continuada como auxilio para aplicação de novos recursos, foi possível identificar os seguintes discursos (Tabela 1). Seguindo esse raciocínio, também foi questionado na entrevista sobre o que os professores esperavam da formação e foi possível registrar (Tabela 1). 
Essas informações permitem analisar o quanto a experiência docente tem influenciado as formações continuadas, visto que o tempo de serviço pedagógico tem corroborado com as perspectivas dos professores nessa formação.

Finalizando a etapa dos questionários, todos os participantes foram convidados a apresentarem-se individualmente, a fim de buscar uma melhor interação do grupo, buscou-se que cada docente e mediador iniciassem sua apresentação falando seu nome, área de atuação e expectativas para a formação.

Foi possível observar que houve interação em todos os momentos das falas dos mediadores sobre os diversos temas abordados em sala, como Educação Ambiental, Formação Docente, Unidade de Conservação, Metodologias Ativas, Trilhas interpretativas, Mata do Pau Ferro e exposição dos recursos pedagógicos de áreas como botânica e zoologia.

Entre as falas percebe-se que os professores (as) reconhecem a importância de trabalhar de forma transdisciplinar as questões relacionadas ao Meio Ambiente, além disso, nota-se que entre o discurso elaborado pelos mediadores, os docentes conseguem transcender e contextualizar para sua realidade de sala de aula, ou seja, a reflexão realizada entre os temas discutidos nas trilhas interpretativas tornou-se "gatilhos" que despertou entre os professores um novo olhar para trabalhar suas áreas de atuação. 
Tabela 1. Diagnostico inicial com os professores das redes públicas de ensino na cidade de Areia, Paraíba, Brasil.

\begin{tabular}{|c|c|c|c|c|}
\hline \multirow[b]{2}{*}{ Docentes } & \multicolumn{4}{|c|}{ Temas } \\
\hline & $\begin{array}{l}\text { Tempo de } \\
\text { atuação }\end{array}$ & $\begin{array}{l}\text { Experiências } \\
\text { anteriores }\end{array}$ & $\begin{array}{c}\text { Percepção acerca da } \\
\text { importância da formação } \\
\text { continuada }\end{array}$ & $\begin{array}{l}\text { Expectativas } \\
\text { com relação } \\
\text { ao minicurso }\end{array}$ \\
\hline Docente (I) & Oito anos & Não & $\begin{array}{l}\text { Sim. Essa forma de ensino } \\
\text { valoriza e levanta o ensino de } \\
\text { hoje. }\end{array}$ & $\begin{array}{l}\text { O melhor } \\
\text { possível }\end{array}$ \\
\hline Docente (II) & Quatro anos & Não & Com toda certeza & $\begin{array}{c}\text { Espero } \\
\text { apreender } \\
\text { novas } \\
\text { ferramentas de } \\
\text { ensino e como } \\
\text { encaixa-las nas } \\
\text { aulas, } \\
\text { relacionando-as } \\
\text { com os } \\
\text { conteúdos }\end{array}$ \\
\hline Docente (III) & 20 anos & $\begin{array}{c}\text { Sim. } \\
\text { Fundamentos } \\
\text { de Educação } \\
\text { (trilhas } \\
\text { ecológicas e } \\
\text { caminhadas) }\end{array}$ & $\begin{array}{l}\text { Sim. Necessita-se sempre } \\
\text { renovar-se e reciclar-se para } \\
\text { melhor assistir o alunado. }\end{array}$ & $\begin{array}{c}\text { Novas } \\
\text { informações } \\
\text { Novas práticas } \\
\text { Valorização e } \\
\text { pertence em } \\
\text { relação a Mata } \\
\text { do Pau Ferro } \\
\end{array}$ \\
\hline Docente (IV) & $\begin{array}{l}\text { Sem } \\
\text { atuação }\end{array}$ & Não & $\begin{array}{c}\text { Sim, com certeza, pois o } \\
\text { docente aprenderá mais e } \\
\text { mais novas técnicas e } \\
\text { aprendizados para sua vida } \\
\text { ética e profissional, ajudando } \\
\text { assim na sua escola e nas } \\
\text { aulas ministradas para seus } \\
\text { discentes com mais } \\
\text { flexibilidade, trabalhando na } \\
\text { compreensão do dia a doa dos } \\
\text { seus alunos. }\end{array}$ & $\begin{array}{l}\text { Local em que } \\
\text { podemos criar } \\
\text { novas } \\
\text { metodologias } \\
\text { para estudo. }\end{array}$ \\
\hline Docente (V) & $\begin{array}{l}\text { Sem } \\
\text { resposta }\end{array}$ & Não & Sim. Com toda certeza & $\begin{array}{l}\text { Espero adquirir } \\
\text { conhecimento } \\
\text { que possa me } \\
\text { complementar } \\
\text { nessa área } \\
\end{array}$ \\
\hline Docente (VI) & 10 anos & $\begin{array}{l}\text { Sim. Economia } \\
\text { solidária, Gira } \\
\text { Mundo } \\
\text { Finlândia, } \\
\text { Ensino para } \\
\text { pessoas com } \\
\text { deficiência } \\
\text { visual } \\
\end{array}$ & $\begin{array}{l}\text { Sim. É importante para } \\
\quad \text { apreender novas } \\
\text { metodologias de ensino e para } \\
\text { utilizar recursos tecnológicos. }\end{array}$ & $\begin{array}{l}\text { Apreender mais } \\
\text { e obter mais } \\
\text { informações de } \\
\text { como usar as } \\
\text { trilhas no } \\
\text { aspecto } \\
\text { pedagógico }\end{array}$ \\
\hline
\end{tabular}


No final do primeiro momento foi realizada uma discussão sobre como os professores conseguiriam trabalhar seus conteúdos em trilhas Interpretativas e entre os temas abordados, foi possível registrar: 1) Importância da mata para o controle do clima, visto que, trabalhariam a importância de manter a conservação das florestas. 2) Trabalhar a preservação das espécies para que não sejam extintas localmente, quanto mundialmente. Um outro tema discutido foi sobre o quanto a 3) natureza transmite sentimentos e percepções, pois permite envolver as pessoas pela sensibilização do cuidado com o meio ambiente e o quanto os sentidos (visão, audição, olfato e tato) permitem sensação de bem estar. 4) Espaço rural e espaço urbano. Além disso, foi citado trabalhos de cunho filosófico, como discussões a respeito de 5) Homem e natureza, o respeito à vida e bioética, explicando que o ser humano faz parte do meio ambiente e, principalmente, como nós, humanos, estamos tratando os outros moradores bióticos e abióticos desse meio, possibilitando fazer reflexões acerca dos problemas decorrentes da nossa sociedade em virtude do mal uso aos recursos naturais.

Os professores mencionaram a importância de envolver todos que fazem parte da escola nos distintos momentos das aulas em campo, mas que, prioritariamente, houvesse a participação de todos os professores, pois assim a interdisciplinaridade traria um novo olhar para o contexto das aulas.

Contudo, os (as) docentes elencam a falta de estímulo em desenvolver novas metodologias para serem inseridas nas escolas e, principalmente, atividades ao ar livre. É perceptível entre as falas dos professores que não existe apropriação por parte dos docentes, sobre a Mata do Pau Ferro, dessa forma, quatro docentes argumentaram terem frequentado poucas vezes a Mata, no entanto, destes quatro professores, dois fazem parte da comunidade circunvizinha da Mata do Pau Ferro. Enquanto os demais professores não conheciam a mata.

\section{Interpretativa \\ O segundo momento da formação docente: a realização da Trilha}

Para o segundo momento, houve a participação de quatro professores, um de Geografia e dois de Educação Física, bem como uma discente do Curso de Graduação em Geografia.

A trilha interpretativa foi brevemente marcada com 10 pontos estratégicos pensados e delimitados previamente e que possibilitassem discutir temas que podem ser trabalhados em sala de aula de forma prática e real. Portanto, utilizamos uma trilha do tipo em atalho, pois permite mostrar uma área alternativa à trilha ou caminho principal, esse tipo de trilha possui início e fim em diferentes pontos. Para o presente caso desenvolvemos uma trilha com distância de $1,16 \mathrm{~km}$ com extensão interessante para praticar esse tipo de atividade, visto que permite analisar uma maior biodiversidade a ser trabalhada, devido ao seu tamanho.

Durante a execução do percurso foi possível analisar o quanto os docentes estavam atentos as explicações dos mediadores, procurando introduzir suas áreas de atuação em vários contextos simbólicos da Mata do Pau Ferro.

0 percurso da trilha despertou vários sentidos e reflexões, tanto pelo espaço que possibilitou uma agradável caminhada pela Mata, quanto pelo engajamento dos professores para com os mediadores e vice-versa, em cada ponto diversos temas foram abordados, desde aqueles assuntos que estavam no cronograma, como novas situações surgiram momentaneamente de forma holística e criativa por todos.

Embora os professores tivessem suas respectivas áreas de conhecimentos, todos faziam perguntas acerca dos assuntos de meio ambiente, cidadania, resíduos sólidos, conhecimento tradicional local (caça, uso de plantas) e tantos outros afins, assim como, faziam retomadas anamnésicas das épocas de ensino básico de biologia e ciências. 
Portanto, buscamos em todos os pontos estratégicos fazer com que os docentes refletissem sobre os temas citados acima, tanto como forma de sensibilização, quanto para aprimorarem suas aulas de maneira que envolvam seres humanos ao meio ambiente.

Para os seis pontos iniciais foi trabalhado o contexto dos recursos naturais. No sétimo ponto foi discutido a importância das funções individuais de todos organismos presente no meio ambiente, portanto, propomos a dinâmica "jogo sobre ecossistema", utilizamos balões de ar que foi representado por um animal por cada professor. Para o primeiro momento dessa dinâmica, cada pessoa encarregada de representar um animal ficou responsável de cuidar do balão. Ao longo da dinâmica, o mediador narrou as consequências negativas que o ambiente tem sido acometido e consequentemente tem influenciado a diminuição de espécies. Portanto, à medida que uma espécie desaparecesse a pessoa ao lado deveria segurar o balão e, assim, sucessivamente. 0 objetivo da dinâmica é mostrar a influência e importância que o ambiente natural possui em sustentar toda biodiversidade e permitir resiliência ao sistema.

No oitavo ponto buscamos fazer os professores refletirem sobre o papel dos recursos naturais junto à comunidade cientifica, desde a necessidade de conservação dos recursos com intuito de preservar as funções ecossistêmicas, quanto para formulação de futuros ativos para bioprospecção de fármacos, por exemplo. Além disso, no ponto nono, foram mencionadas as pessoas que moram circunvizinhos a Mata do Pau Ferro, tanto do ponto de vista cultural, em virtude da relação que moradores possui com a mata, quanto da importância do conhecimento tradicional para o manejo dos recursos presentes na mata.

No último ponto foi realizado um grupo focal como forma de feedback sobre as percepções dos professores em relação a formação continuada. Foi conduzido por perguntas geradoras, pois permitiu discutir diversos pontos de vista, como a exemplo: 0 que os professores acharam do minicurso? Como conseguiriam aplicar as trilhas para o seu contexto local? 0 que poderia ser melhorado? Para registro das falas dos professores, cada área de atuação será indicada com números romanos: Professores de Educação Física (I) e (II), Professoras de Geografia (III) e (IV) e Discente de Geografia (V).

Houve similaridade entre as respostas sobre o que os professores e professoras acharam da realização do minicurso. Entre as alegações, todos os professores demostram sentir-se entusiasmados e despertados com uma nova forma de olhar a Mata do Pau Ferro. Assim como retrata a fala da professora (IV):

Sou apaixonada pela mata... Me sinto feliz quando pessoas vem até aqui com um novo olhar para explorar as potencialidades que muitas vezes por estarmos acostumados aqui, passam despercebidos [...]. Professora (IV).

Ao questionar as formas que cada profissional poderia transportar da metodologia aplicada no minicurso para sua realidade ficou perceptível a aspiração que os docentes tinham em explorar suas temáticas de forma transdisciplinar, já que buscavam envolver diversos contextos e convidar professores de outras áreas para conduzirem seus estudantes nas trilhas interpretativas. Assim, cada professor pensou diferentes situações em que poderiam trabalhar sua disciplina nas trilhas:

Trabalhar esportes do tipo corrida, por que como a mata é fechada disponibiliza muito oxigênio; Trabalhar com eles o respeito e preservação da natureza. Professor (I Educação Física).

Pretendo reunir outros professores. Trabalhar solo, clima e exemplos práticos. Fazer com que os alunos percebam que fazem parte do Meio Ambiente. Professor (II Geografia). 
Trabalhar o lúdico por meio da Educação Física, Cultura e Teatro. Poderíamos trabalhar a encenação, isso ajudaria memorizar e apreender termos científicos, mostrando de forma histórica o significado dos recursos, por exemplo. A parte de encenação chamaria muita atenção do aluno e talvez ele conseguiria absorver melhor. Professor (III Educação Física).

Sempre trazemos crianças para Mata, ficaria muito bom trabalhar histórias infantis, como "a história do chapeuzinho vermelho no bosque"... deixaria a trilha mais significativa, gratificante e com aprendizagem. Professor (IV Geografia).

Estas informações trazem o significado social das especificidades profissionais de cada docente, permitindo que todos direcionem um olhar holístico de sua área de conhecimento para o processo de ensino e aprendizagem.

Além disso, foi possível observar que os professores procuravam estabelecer formas de demostrar a importância que existe dentro das formações continuadas, tanto do ponto de vista da aprendizagem para com eles, quanto para construção de novas ferramentas a serem trabalhadas nos seus locais de ação pedagógica. Destacamos as seguintes falas dos professores:

Essa formação possibilitou algo melhor para mim, fez mostrar que eu faço parte de tudo desse meio. Dessa forma fica tudo mais fácil para levar essas informações para eles (alunos). Professora (III).

Essa parceria escola e universidade é muito interessante e ainda ouso dizer: escola, universidade e comunidade. Professora (IV).

É de extrema importância que a escola e universidade ao planejar e programar suas ações pedagógicas procure envolver a comunidade para construção do conhecimento, tanto como forma de engajamento, quanto como retorno das ações criadas dentro de espaços formativos.

\section{Discussão}

\section{Primeiro momento da formação docente: troca de experiências e conhecimentos na sala de aula}

A finalidade de convidar todos os professores e professoras da rede estadual da cidade de Areia é vislumbrada pela necessidade de trabalhar de forma transversal temas relacionados ao Meio Ambiente (Brasil, 1999) e que deve ser desenvolvida como uma prática educativa e integrada, contínua e permanente em todos os níveis e modalidade do ensino formal de forma consciente e contextualizada (Estevam e Gaia, 2017). Embora essa área seja compreendida em seus aspectos biológicos, químicos e físicos, há uma necessidade que forneça uma visão holística para necessidade de vislumbrar dimensões sociopolíticas para formação da cidadania (Abílio e Guerra, 2005).

Corroborando com a literatura, as formações continuadas devem levar em consideração as características sociais e os pressupostos das práticas docentes, ou seja, fazer os docentes refletirem suas práticas (Florentino e Abílio, 2016).

Formações de cunho fechado que buscam transmitir informações e qualificações sem enxergar a realidade dos docentes tem-se tornado defasada, pois não há envolvimento de construção junto aos professores. São características como estas que podem ter corroborado para que os professores do presente estudo não tenham participações em formação continuada. Essa problemática tem sido estudada por Pacheco (2008) ao longo de seus registros na área de educação, o qual tem feito diversas reflexões acerca de formações continuadas no Brasil e tem destacado o quanto tem se tornado avaliativa, acumulativa e pouco reflexiva. 
Fazendo uma análise dos registros obtidos no diagnóstico desse estudo é possível verificar o quanto os professores priorizam a necessidade de formações para um melhor desempenho de suas aulas e consequentemente desenvoltura para aprendizagem dos estudantes. Todavia, para que as formações se tornem mais proveitosas, necessita-se que haja um novo olhar para as novas formações acadêmicas e, sobretudo, que emancipe o professor como coautor da sua própria formação continuada de forma prática, crítica e reflexiva (Pimenta e Ghedimn, 2002).

Esse novo olhar corrobora com as falas dos professores dessa formação no que tange sobre como todos se sentem perante essa nova forma de enxergar os recursos disponíveis do meio ambiente e a capacidade que possuem em desenvolver aulas diferenciais.

\section{o segundo momento da formação docente: a realização da Trilha Interpretativa}

As trilhas interpretativas têm como propósito estimular as pessoas pela percepção com objeto, permitindo o envolvimento das percepções e, especialmente, formando representações por meio dos sistemas sensórias. As trilhas permitem refletir, questionar, observar e descobrir os sentidos pré-estabelecidos pelos mediadores como ferramenta de estimulação para interpretação do mundo (Leff, 2003).

$\mathrm{Na}$ literatura existem diversas formas de demarcação de trilhas ecológicas (Mitraud, 2003), Trilha Circular que tem possibilidade de voltar ao ponto de partida sem repetir o percurso do retorno; Trilha em Oito eficiente em áreas de menor tamanho pois possibilita usar os espaços; Trilha Linear tem como objetivo conectar o caminho principal com outros caminhos. Contudo, trilhas do tipo atalho são apropriadas para o presente estudo devido às particularidades que buscamos estudar, pois oferece diversas alternativas de controle.

No entanto, para o segundo momento da formação, pouquíssimos professores participaram do encontro na Mata do Pau Ferro e, vale salientar, que apenas os professores que afirmaram já conhecer a mata foram os que participaram do segundo momento, enquanto aqueles que não conheciam a mata não se propuseram a conhecer a mata, e nem essa nova metodologia pedagógica.

Esta situação torna-se preocupante, visto que poucos professores se apropriam dos recursos naturais presentes no município como ferramenta pedagógica, comprometendo os meios de divulgação e transposição de metodologias para sua ação didática.

Registros que tratem de formações de professores para o uso de trilhas interpretativas como ferramenta pedagógica encontra-se escasso nos meios acadêmicos. Embora haja uma ampla divulgação de estudos que abordem o uso de Trilhas interpretativas para incrementar as concepções de estudos educacionais como aventura, passeios ecológicos (Saul et al., 2011; Tabanez et al., 1997) e de grupos externos (projetos universitários) que viabilizam os estudantes participarem de trilhas, assim como registrado no Parque Nacional do Mindu, Manaus-AM, por Alves et al. (2018), e na Ilha do Marajó-PA, por Repolho et al. (2018).

As concepções do segundo momento da formação permitiram que os docentes construíssem um aparato de conhecimentos a respeito da aplicabilidade de suas áreas de atuação para as trilhas interpretativas. Esse momento permitiu o exercício do pensamento crítico, possibilitando que os professores saíssem de suas gaiolas fechadas, permeando para busca da transformação de saberes por meio do conflito de ideias e valores que cada professor apresentou, corroborando com o que Sauvé e Orellana (2000) argumentam na formação continuada de professores para educação ambiental. 


\section{Conclusões}

Dentre os contextos citados pelos professores é notório a importância retratada sobre a necessidade de envolver universidade e sociedade local com intuito de aproximação e retorno. As universidades têm desenvolvidos arcabouços teóricos que têm auxiliado no desenvolvimento de ferramentas para construção de formações. E essas ações mostram a relevância do nosso estudo, visto que, os professores são os principais mediadores para o uso de metodologias em ação. Portanto, no decorrer dessa pesquisa e formação, propomos algumas orientações que poderão servir para as futuras formações continuadas. 1) Evitar desenvolver formações durante retas finais do período letivo das escolas, visto que os professores estarão sobrecarregados de atividades; 2) Realizar convite para formação dos professores, principalmente, durante reuniões do colegiado escolar, assim terá maior probabilidade da informação alcançar todos professores; 3) Formações de curto tempo, recomenda-se que seja estruturado e desenvolvido para que aconteça em dias seguidos; 4) Sempre que possível convidar o coordenador do projeto para participar dos primeiros contatos com o espaço escolar.

Portanto, práticas de atividades educacionais em ambientes com presença de natureza devem abordar questões problematizadoras sobre contextos socioambientais, de tal forma que permita a sensibilização das pessoas. 0 fato dos professores refletirem sobre sua atuação docente e construir a partir das trilhas interpretativas formas diversificadas de aplicar suas aulas, permite que os professores desenvolvam futuras aulas. No entanto, mesmo sendo um tema transversal e bastante argumentado nos tempos atuais, nota-se que os professores ainda precisam ser despertados em trabalhar metodologias ativas de maneira contextualizada demostrando como utilizar conteúdos para realidade dos estudantes.

\section{Agradecimentos}

Aos professores e professoras das redes estaduais da cidade de Areia, Paraíba. Ao PROLICEN (Programa de Licenciatura) pelo apoio financeiro utilizado para otenção dos dados.

\section{Conflito de interesses}

Os autores declaram não haver conflitos de interesse.

\section{Referências}

Abílio, F. J. P.; Guerra, R. A. T. A temática ambiental no ensino de Ciências: um projeto de formação continuada de professores de ensino fundamental do Município de Cabedelo-PB. Anais do Congresso Internacional de Formação Continuada e Profissionalização Docente, João Pessoa, v. 1. p. 520-552, 2005.

Alves, F. E.; Oliveira, I. S.; Alves, C. N. Trilha ecológica pedagógica: um caminho para o ensino da educação ambiental em uma escola pública no Município de Manaus (AM).

Revista Brasileira de Educação Ambiental, v. 13, n. 2, p. 153-169, 2018. https://doi.org/10.34024/revbea.2018.v13.2468

Brasil. Lei no 9.795, de 27 de abril de 1999. Dispõe sobre a educação ambiental, institui a Política Nacional de Educação e dá outras providências. Disponível em: <http://www.planalto.gov.br/ccivil_03/LEIS/L9795.htm>. Acesso em: 21 jan. 2020. 
Brasil. Ministério da Educação. Secretaria de Educação Fundamental. Parâmetros Curriculares Nacionais: terceiro e quarto ciclos - apresentação dos temas transversais: Brasília: MEC/SEF, 1999.

Demo, P. Dialética da felicidade: olhar sociológico e pós-moderno. Petrópolis: Vozes, 2001. v. 1.

Deus, A. M.; Mendes, B. M. M. Formação de professores: valorizar e ater-se ao essencial do currículo e da prática pedagógica. In: Mendes-Sobrinho, J. A. C.; Lima, M. G. S. B. (Orgs.). Formação, prática pedagógica e pesquisa em educação: retratos e relatos. Teresina: EDUFPI, 2011. p. 17-32.

Estevam, C. S.; Gaia, M. C. M. Concepção ambiental na educação básica: Subsídios para estratégias de educação ambiental. Revista Brasileira de Educação Ambiental, v. 12, p. 195-208, 2017.

FAMUP - Federação das Associações de Municípios da Paraíba. 2013. Portal dos Municípios da Paraíba. Disponível em: <http://www.famup.com.br/portal/index.php>. Acesso em: 25 jan. 2020.

Flick, U. Triangulation revisited: Strategy of validation or alternative? Journal for the Theory of Social Behavior, v. 22, p. 175-197, 1992. https://doi.org/10.1111/j.14685914.1992.tb00215.x

Florentino, H. S.; Abílio, F. J. P. Formação continuada de professores: vivências de educação ambiental no contexto do semiárido. Revista Reflexão e Ação, v. 24, p. 334-354, 2016. https://doi.org/10.17058/rea.v24i2.3849

Freire, P. Pedagogia do oprimido. São Paulo: Paz e Terra, 2006.

Gemignani, E. Y. M. Y. Formação de professores e metodologias ativas de ensino-aprendizagem: ensino para compreensão. Revista Fronteira da Educação, v. 1, p. 1-27, 2012.

Gil, A. C. Como elaborar projetos de pesquisa. São Paulo: Atlas, 1991.

Gonzaga, P. C. A trajetória formativa do professor de Biologia e suas contribuições para o processo de alfabetização biológica. Teresina: Universidade Federal do Piauí, 2013. (Dissertação de mestrado).

Guerra, R. A. T.; Abílio, F. J. P. Educação ambiental na escola pública. João Pessoa: Foxgraf, 2006.

Hammes, V.S. Percepção ambiental. In: Hammes, V.S. Proposta metodológica de macroeducação. São Paulo: Embrapa, 2004. v. 2. p. 128-130.

IBGE - Instituto Brasileiro de Geografia e Estatística. Censo 2010. Disponível em: <https://cidades.ibge.gov.br/brasil/pb/areia/panorama>. Acesso em: 05 ago. 2019.

Leff, E. A complexidade ambiental. São Paulo: Cortez, 2003.

Leff, E. Educação ambiental e desenvolvimento sustentável. In: Reigota, M. (Org.). Verde cotidiano: o meio ambiente em discussão. Rio de Janeiro: DP\&A, 1999. p. 111-129.

Minipoli, R.; Storti, G.; Hammes, V. S. Roteiro de trilha interpretativa. In: Hammes, V. S. Proposta metodológica de macroeducação. São Paulo: Embrapa, 2004. v. 2. p. 303-308.

Mitraud, S. Manual de ecoturismo de base comunitária: ferramentas para um planejamento responsável. Brasília: WWF Brasil, 2003. 
Morgan, D. L. Focus groups. Annual Review of Sociology, v. 22, p. 129-152, 1996. https://doi.org/10.1146/annurev.soc.22.1.129

Pacheco, J. Escola da Ponte: formação e transformação da educação. 4. ed. Petrópolis: Vozes, 2011.

Pimenta, S. G.; Ghedin, E. (Orgs.). Professor reflexivo no Brasil: gênese e crítica de um conceito. São Paulo: Cortez, 2002.

Prodanov, C. C.; Freitas, E. C. Metodologia do trabalho científico: métodos e técnicas da pesquisa e do trabalho acadêmico. 2. ed. Novo Hamburgo: Universidade Feevale, 2013.

Repolho, S. M.; Campos, D. N. S.; Martins, A. C. C. T.; Assis, D. M. S.; Pontes, A. N. Percepções ambientais e trilhas ecológicas: concepções de meio ambiente em escolas do Município de Soure, Ilha de Marajó (PA). Revista Brasileira de Educação Ambiental, v. 13, p. 66-84, 2018. https://doi.org/10.34024/revbea.2018.v13.2541

Rudio, F. V. Introdução ao projeto de pesquisa científica. 30. ed. Rio de Janeiro: Vozes, 2002.

Saul, P. F. A.; Stranz, A. ; Zerfass, H. ; Fuhro, D. Caracterização ambiental da trilha do Passo do Louro (Canela, RS) para atividades em educação ambiental através da análise da paisagem. Anais do V Congresso de Ecologia do Brasil - Ambiente e Sociedade, Porto Alegre, Universidade Federal do Rio Grande do Sul, p. 363, 2001.

Sauvé, L.; Orellana, I.; Qualman, S. La educación ambiental: una relación constructiva entre la escuela y la comunidad. Montreal: EDAMAZ \& UQÀM, 2000.

Silva, E. M. A.; Araújo, C. M. Reflexão em Paulo Freire: uma contribuição para formação continuada de professores. Anais do V Colóquio Internacional Paulo Freire, Recife, 2005.

Silva, M. M. P. Curso de Agentes Multiplicadores em Educação Ambiental. Fase II. Projeto de Extensão vinculado à Pro-Reitoria de Extensão e Assuntos Comunitários; 05.10.120.11- Aprovado no edital PROBEX 2011-2012 da Pró-Reitoria de Extensão e Assuntos Comunitários. Campina Grande: UEPB, 2011. (Curso de extensão).

Tabanez, M. F.; Padua, S. M.; Souza, M. G. Avaliação de trilhas interpretativas para educação ambiental. In: Padua, S. M.; Tabanez, M. F. (Orgs). Educação ambiental: caminhos trilhados no Brasil. Brasília: Instituto de Pesquisas Ecológicas, 1997. p. 90-102

Veiga, I. P. Caminhos da profissionalização do magistério. Campinas: Papelivros, 1998.

Informação da Licença: Este é um artigo Open Access distribuído sob os termos da Licença Creative Commons Attribution, que permite uso irrestrito, distribuição e reprodução em qualquer meio, desde que a obra original seja devidamente citada. 